\title{
Condutas Gerenciais e suas Raízes: uma Proposta de Análise à Luz da Teoria da Estruturação
}

\author{
Gelson Silva Junquilho
}

\begin{abstract}
Resumo
O objetivo deste artigo é identificar condutas gerenciais oriundas da ação humana nas organizações. Tomando-se como pressuposto que aquela mesma ação não é determinada por estruturas sociais, mas por elas condicionada, mostra-se aqui como os gerentes reproduzem, em seus cotidianos, traços da sociedade brasileira. A pesquisa de campo foi realizada nas Secretarias de Estado do Governo do Espírito Santo, tomando-se como unidade de análise os servidores estaduais ocupantes de cargo de chefia, por no mínimo dois anos, em nível dos órgãos centrais, no período de janeiro de 1995 a dezembro de 1998. O método utilizado foi o estudo de caso, levantando-se dados a partir de entrevistas. A estratégia metodológica envolveu a indissociabilidade das condutas estratégicas dos sujeitos organizacionais de elementos da estrutura social - a dualidade da estrutura. Os dados revelam que os gerentes contribuem, com sua ação, para a reprodução de propriedades estruturais brasileiras. O conhecimento dessa situação, ou seja, a cognoscitividade que possuem a respeito desse contexto, permite-lhes seguir em frente, definindo condutas apropriadas a cada momento, em processo de monitoramento constante da realidade que os cerca.
\end{abstract}

Palavras-chaves: teoria da estruturação; condutas gerenciais; reprodução social.

\begin{abstract}
The object of this article is the identification of managerial conducts, originated from human action in organizations. Taking for granted that the organizational actors do not act determinated by social structures, but conditioned by elements, rules and resources pertaining to the social structure of the reality in which they are inserted, it is shown here how such managers reproduce some features of Brazilian society in their daily routines. The field was carried out in the State Secretariat Offices of Espirito Santo State government, taking as a unit for analysis those state civil servants occupying the position of head for at least two years, at the central agencies level, during the period January 1995 - December 1998. The method used was that of a case study, collecting data from interviews. The methodological strategy involved the indissolubility between the strategic conduct of the organizational subjects and elements of the social structure - the duality of structure. Data revealed that the managers contribute, with their action, for the reproduction of some Brazilian structural characteristics. Their knowledge of such characteristics, that is, their cognoscitivity concerning that context, allows them to go ahead, defining the appropriate conduct for each moment, in a process of constant monitoring of the reality around them.
\end{abstract}

Key words: structuration theory; managerial conducts; social reproduction. 


\section{INTRODUÇÃO}

A ação humana nas organizações é definida a partir de um processo de construção social que ocorre ao longo do tempo e do espaço, constituindo-se num conjunto de práticas complexas e distintas que depende, entre outros fatores, da maneira particular como cada ator organizacional apreende papéis a ele designados, da relação com outras pessoas, bem como dos contextos culturais nos quais estão inseridos (Stewart, 1989; Whitley, 1989; Watson, 1994). Toma-se ainda como pressuposto que aquela mesma ação é resultado de práticas sociais (Reed, 1989) e, como tal, deve ser compreendida a partir de relações histórico-sociais em dada sociedade (Alvesson e Willmott, 1996), isto é, vinculando-se ação e estrutura, por meio de processo dinâmico de construção e reconstrução da vida social, caracterizado por aquilo que Giddens $(1979,1984)$ denominou de dualidade da estrutura. Esse conceito, central na Teoria da Estruturação, definida pelo mesmo Giddens, é que permite, por um lado, o estudo analítico da ação desenvolvida por atores individuais e, por outro lado, o exame dos impactos da estrutura sobre aqueles mesmos agentes, destacando-se que as estruturas tanto restringem como facilitam a própria ação, permitindo, assim, a possibilidade de que os atores possam alterar comportamentos, tornando-se plausível um processo contínuo de mudança social. Em outras palavras, os atores não estão passivos ao determinismo das regras sociais.

Desse modo, a ação humana não é simplesmente restringida pelas circunstâncias nas quais ela ocorre, podendo igualmente ser facilitada por elas. Isto é, as estruturas e circunstâncias às quais os seres humanos estão submetidos condicionam parcialmente o que eles pensam e fazem, já que eles podem, por outro lado, apoiando-se ainda nessas mesmas estruturas e circunstâncias, reinventá-las por meio da ação (Orlikowski e Robey, 1991; Watson, 1994; Rouleau, 1995; Rouleau e Junquilho, 1998). Então, pensar a ação humana nas organizações como construção ou fenômeno social, envolve a análise conjunta da própria ação, bem como os efeitos de determinadas propriedades estruturais sobre essa ação, seja restringindo-a e/ou facilitando-a (Giddens, 1984).

Logo, o objetivo maior deste artigo é mostrar como a dualidade da estrutura é útil para a análise organizacional, permitindo a compreensão de como ocorre o processo de estruturação (Giddens, 1984) da ação humana, ou seja, por que tipo de regras e recursos inerentes a sistemas sociais próprios de uma dada estrutura social, certas práticas sociais são construídas no cotidiano de trabalho. Para tanto, serão apresentados resultados de um estudo que teve como problema central a 
seguinte questão: como a ação gerencial, identificada por meio de certas condutas sociais, é condicionada por propriedades estruturais da sociedade brasileira? A hipótese central foi a de que propriedades estruturais (raízes) daquela mesma sociedade são as mesmas que ora habilitam e ora restringem a ação gerencial, sendo esta última, assim, tão somente condicionada e não determinada pelas primeiras.

\section{A Contribuição da teoria da Estruturação para a Compreensão da Ação Humana nas Organizaçóos}

Whittington (1992) e Sahay e Walsham (1997) são categóricos ao apontar a utilidade da Teoria da Estruturação, concebida pelo sociólogo britânico Anthony Giddens, como ferramenta de grande importância para a análise organizacional. De fato, essa teoria permite vincular a ação cotidiana dos atores organizacionais, em nível micro, à questão mais ampla das estruturas sociais de uma dada realidade sem, entretanto, estabelecer determinismos entre ação e estrutura e vice-versa. Para tanto, o conceito de dualidade da estrutura proposto por Giddens (1979, 1984) é uma alternativa ao dualismo relacionado ao sujeito e ao objeto nas Ciências Sociais, em que a estrutura é tomada como externa, suprema e limitadora da ação de indivíduos - tradições funcionalista e estruturalista.

Giddens $(1979,1984)$, contrapondo-se à visão dicotômica entre aquelas duas correntes do pensamento social, afirma que existe relação de reciprocidade entre ação e estrutura, ou seja, não se pode pensá-las uma sem a outra. Para tanto, inicia o debate criticando o conceito clássico de estrutura social descrito a partir de duas características básicas: como sendo pilar de sustentação de um edifício ou até mesmo a constituição anatômica de um corpo, bem como restritiva (constraint) ou modeladora da ação humana. Segundo o mesmo autor, tratar a estrutura como algo vinculado à idéia exclusiva de restrição é a mesma coisa que considerá-la como variável independente e autônoma em relação à ação humana. Isso significa, na prática, o reforço ao dualismo entre sujeito e objeto, ou seja, interpretar a ação como sendo unicamente determinada pela estrutura social, não se dando voz aos atores sociais, isto é, desconsiderando-se sua capacidade de intervenção na vida social, seja reproduzindo, seja transformando aquela mesma estrutura.

Assim o seu conceito de estrutura é dado como sendo o conjunto de "regras e recursos, recursivamente implicados na reprodução dos sistemas sociais" (Giddens, 1984, p.377). A idéia de recursividade indica que as condutas humanas não são criadas pelos atores sociais, mas recriadas por eles, por suas próprias formas e 
meios utilizados para se expressarem como atores. As regras representam convenções sociais em que o seu conhecimento pelos atores inclui também o conhecimento dos contextos nos quais se aplicam, constituindo-se como guias de orientação para a conduta humana. Os recursos referem-se às capacidades, à disposição dos atores para fazer com que as coisas aconteçam. A partir daí, a estrutura não é vista como existindo exteriormente à ação humana, mas concebida como virtual, à medida que só se concretiza pela reprodução da vida social, isto é, ela não se viabiliza independentemente da ação humana. Daí investigar "a estruturação das práticas sociais é procurar explicar como é que a estrutura se produz por intermédio da ação e, reciprocamente, como é que a ação é constituída estruturalmente" (Giddens, 1996, p.183).

Dada essa noção de estrutura, Giddens $(1979,1984)$ constrói o conceito, que é central na Teoria da Estruturação, qual seja, o da dualidade da estrutura, buscando a demonstração de que a estrutura não deve só ser equiparada à idéia de restrição ou coerção, mas também, simultaneamente, à de facilitadora. Por essa noção da dualidade da estrutura, o autor demonstra que propriedades institucionais dos sistemas sociais são criadas pela ação humana ao mesmo tempo que servem de apoio para configurar (shape) essa ação, dado que

"cada ato que contribui para a reprodução da estrutura é também um ato de produção, um novo empreendimento e, enquanto tal, pode iniciar a mudança pela alteração dessa estrutura, ao mesmo tempo que a reproduz - assim como o significado das palavras muda no e através do uso" (Giddens, 1996, p.146).

O conceito de propriedades institucionais ou estruturais surge a partir daquilo que o mesmo autor define como instituições, isto é, aqueles aspectos que são mais duradouros na vida social. Dessas mesmas instituições são derivadas as propriedades estruturais que representam as características que se encontram institucionalizadas nos sistemas sociais, garantindo-lhes solidez através do tempo e espaço (Giddens, 1984). É importante observar, ainda, que a idéia de dualidade da estrutura permite a superação do dualismo estrutura e ação como fenômenos isolados e independentes, bem como a interpretação de que a estrutura não é determinante da ação humana, mas sua condicionante. Assim é pela dualidade da estrutura que se explica a possibilidade de os atores reproduzirem relações sociais ao longo do tempo e do espaço, à medida que as propriedades estruturais de uma dada sociedade são as mesmas que restringem e habilitam a sua ação cotidiana.

A estrutura, por ser virtual, ou seja, não existir concretamente, torna-se propriedade abstrata dos sistemas sociais, definidos por Giddens (1984, p.377) como sendo "a padronização de relações sociais ao longo do tempo-espaço, entendidas como práticas reproduzidas". Assim os sistemas sociais não são 
estruturas, mas possuem propriedades estruturais específicas a cada um deles. A estruturação desses mesmos sistemas sociais é então dada pelo estudo dos "modos como tais sistemas, fundamentados nas atividades cognoscitivas, de atores localizados que se apóiam em regras e recursos na diversidade de contextos de ação, são produzidos e reproduzidos em interação" (Giddens, 1989, p.20).

Conciliar estrutura e ação humana pela Teoria da Estruturação, passa também pela consideração de que todo ator social é cognoscitivo e reflexivo, tomando-se como princípio básico que ele sabe como definir sua forma de agir perante a vida social. Cognoscitivo porque possui um conjunto de habilidades e capacidade de domínio de determinadas convenções sociais que o orientam na vida social cotidiana. O conhecimento que ele detém dessas mesmas convenções lhe permite agir corretamente, definindo a forma como prosseguir na diversidade dos contextos cotidianos nos quais está envolvido. Já a reflexividade refere-se ao fato de o ser humano ser capaz de observar e entender, rotineiramente, o que faz e enquanto o faz e, ainda, estar sempre atento quanto à forma de se conduzir em relação a terceiros, considerando também que esses terceiros fazem o mesmo em relação a ele (Giddens, 1984; Orlikowski, 1992; Simard, 1992; Rouleau, 1995; Saranson, 1995).

A cognoscitividade pressupõe familiaridade do ator social com os contextos em que se desenrolam as ações humanas. A partir desse savoir faire, ele é capaz de desenvolver certas habilidades e rocedimentos que lhe garantem a ação em seus diversos relacionamentos sociais cotidianos. No dizer de Giddens (1989, p.301), a cognoscitividade deve ser entendida como "tudo que os atores sabem (crêem) acerca das circunstâncias de sua ação e da de outros, apoiados na produção e reprodução dessa ação, incluindo tanto o conhecimento tácito quanto o discursivamente disponível". De acordo com a Teoria da Estruturação, é o uso desses saberes, compartilhados e comuns aos atores sociais ou agentes, que possibilita a produção e reprodução da vida social, permitindo-lhes, do mesmo modo, dar significados às suas ações.

Giddens $(1979,1984)$ destaca ainda que a vida social, diferentemente das coisas da natureza, dá origem à idéia de prática social, tendo esta a ver com procedimentos, métodos e técnicas, executados e manejados de forma apropriada por esses mesmos agentes sociais, tomando como base a consciência que eles detêm sobre os procedimentos de uma ação. Esse conhecimento mútuo (mutual knowledge) é compartilhado pelos atores sociais, que sabem como se comportar ou prosseguir em determinadas situações cotidianas. A prática social concilia condutas e atos de agentes humanos sem, por outro lado, desconsiderar as estruturas sociais que são referências para aqueles mesmos agentes em processo de interação social (Goffman, 1983), tornando possível a dualidade macro e microssocial, sem privilégio de um nível sobre o outro ou até de sua independência mútua, mas como pólos 
complementares. Assim, "as práticas sociais podem ser estudadas, em primeiro lugar, do ponto de vista da sua constituição como séries de atos 'desencadeados' pelos atores, em segundo, como constituindo formas de interação, envolvendo a comunicação de significado, em terceiro, como constituindo estruturas que pertencem às 'coletividades' ou 'comunidades sociais'”' (Giddens, 1996, p.121).

A ação envolve também a criação de uma diferença por parte do agente. Desse modo, vincula-se ao conceito de poder, entendendo-se este, em sentido geral, como capacidade transformadora, ou seja, como a capacidade de um agente intervir numa dada realidade ou em determinados cenários, alterandoos de alguma maneira. O poder é operacionalizado pela mobilização, pelos agentes, daquilo que Giddens $(1984,1987)$ denomina de recursos ou facilidades e que se classificam em dois tipos: recursos alocativos, referindo-se àqueles relativos à ordem estrutural econômica, isto é, àquelas formas de dominação que têm que ver com o controle sobre propriedade material de bens, objetos e fenômenos materiais; recursos de autoridade, inerentes ao domínio sobre atividades do seres humanos.

Nesse sentido, todos os sistemas sociais reproduzem formas de dominação que são regularizadas ao longo do tempo e do espaço. Há que se ter em conta que essa reprodução de relações de dominação não pressupõe total dependência dos agentes em relação a quem os domina, mas também autonomia; em outras palavras, as relações de poder não são somente limitadoras da ação, mas também permitem abertura a quem está em posição de subordinação para influenciar a ação daquele que o subordina, isto é, os agentes subordinados podem dispor de certos recursos que lhes abrem espaço para a ação. Essa possibilidade é o que Giddens denomina de dialética do controle.

A questão da estruturação dos fenômenos sociais passa pela compreensão da reprodução da estrutura, por meio de sistemas sociais. A partir da noção de dualidade da estrutura, é então proposto o modelo da dualidade da estrutura em interação (Giddens 1979, 1984, 1996), que representa a reprodução da vida social. Esse modelo constitui o processo pelo qual o autor concilia estrutura e ação social, partindo sempre do princípio de que a mediação da conduta humana pela estrutura, bem como a constituição dessa mesma estrutura por meio da ação humana, acontecem de forma simultânea, exprimindo a vinculação entre as rotinas das ações cotidianas e propriedades institucionalizadas da vida social.

Assim, o modelo da Dualidade da Estrutura em Interação é composto pela associação do domínio da estrutura ao domínio da ação humana, por meio de três modalidades responsáveis pelo vínculo entre aqueles dois domínios. O domínio da estrutura (institucional) corresponde a três dimensões: significação, dominação e legitimação. O domínio da interação (ação humana) é constituído pelas seguintes 
dimensões: comunicação, poder e sanção. Cada uma dessas dimensões encontra seus correspondentes nos dois domínios. A Figura 1, a seguir, mostra que a vinculação entre os dois domínios é estabelecida por três modalidades: os esquemas interpretativos, as facilidades ou recursos e as normas, consubstanciando o modelo da Dualidade da Estrutura em Interação (Giddens, 1989).

Figura 1: Modelo da Dualidade da Estrutura em Interação

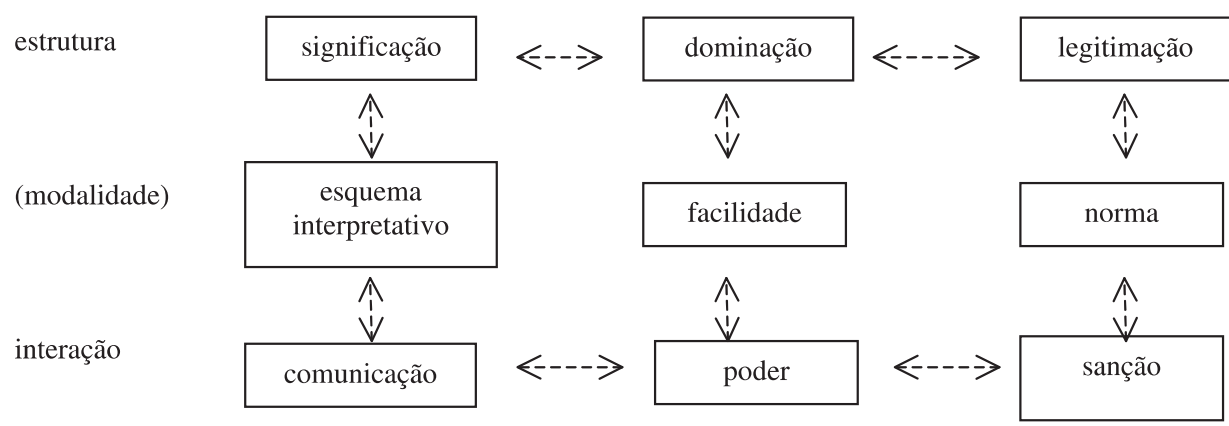

Fonte: Giddens (1989, p.23).

As modalidades são instâncias mediadoras entre a estrutura e a interação no processo de re/produção do social. Essas modalidades são utilizadas pelos atores na produção das dimensões de interação, ao mesmo tempo que são meios para a reprodução dos componentes estruturais (dimensões da estrutura) naquelas mesmas dimensões da interação. As modalidades expressam a cognoscitividade dos agentes sociais em relação a cada dimensão da estrutura. Os esquemas interpretativos expressam os conjuntos de conhecimentos dos atores sociais acerca da realidade $\mathrm{e}$ que lhes permitem compartilhar, interpretar e comunicar significados nos processos de interação cotidiana. Assim os esquemas interpretativos representam os condicionamentos (constraints) da dimensão estrutural, isto é, comportam significados que dizem respeito a regras sociais que, ao mesmo tempo, informam, restringem, bem como tornam possível a comunicação no nível da interação. Em contrapartida, esses mesmos esquemas interpretativos podem ser transformados na sua utilização na vida social cotidiana pela ação humana.

As facilidades ou recursos são modalidades que se referem aos meios que os atores utilizam como forma de alcançar objetivos e resultados que lhes interessam. É por meio dessas facilidades que o poder, na dimensão interação, é exercido. De acordo com Giddens $(1979,1984)$, o poder é tomado como a capacidade dos agentes, por meio de sua ação, de transformar a realidade na qual se inserem, ou seja, de suas habilidades para fazer uma diferença ou agir de uma maneira ou de outra. $\mathrm{O}$ exercício do poder reafirma, pelo ponto de vista da dimensão estrutura, a dominação 
na vida em sociedade. Partindo-se do pressuposto de que todos os sistemas sociais são caracterizados pela assimetria de recursos à disposição dos agentes, a estrutura de dominação pode sempre ser modificada, quando aquela mesma assimetria é posta em cheque na dimensão da interação (Orlikowski e Robey, 1991).

As normas referem-se aos conjuntos de regras, códigos e convenções que orientam a conduta humana, definindo direitos e obrigações, o que é certo ou errado, constituindo-se como ordem moral no domínio da interação. É importante observar que regras tanto facilitam como restringem a ação social, não possuindo, portanto, caráter determinista em relação a essa última. Essas normas, no domínio da estrutura, permitem a legitimação de determinada ordem e sua sanção pelos agentes no domínio da interação. Assim elas são responsáveis pela articulação, bem como pela sustentação de comportamentos legitimados institucionalmente, reforçando ordens normativas na vida social cotidiana.

Giddens $(1979,1984)$, por meio do modelo da dualidade da estrutura, quer enfatizar que toda interação humana, composta pelas dimensões da comunicação, poder e sanção, e mediada pelos esquemas interpretativos, recursos e normas, é condicionada, em nível de estrutura, pelas dimensões da significação, dominação e legitimação, ao mesmo tempo que é, também no domínio da própria interação, constituída a estrutura social. Ainda conforme o mesmo autor, é exatamente por meio do vínculo entre os domínios da estrutura e da interação humana que se constitui o processo de estruturação, sendo a divisão entre as dimensões da estrutura e da interação apenas analítica, dado que o processo de estruturação pressupõe o vínculo entre estrutura e interação pela intermediação das modalidades. No entender de Willmott (1981, 1987), os sistemas de significação permitem a comunicação entre os agentes pelo uso de esquemas interpretativos. Por meio dos sistemas de dominação e de suas facilidades o poder é exercido. Já a sanção é viabilizada pela aplicação de normas institucionalizadas, legitimadas socialmente em nível estrutural.

Assim, o modelo da Dualidade da Estrutura em Interação (Giddens, 1984) constitui poderoso instrumento para a compreensão da ação humana nas organizações, à medida que permite um olhar mais ampliado sobre ela, possibilitando o seu vínculo necessário ao plano da estrutura social, enriquecendo sobremaneira os seus significados analíticos, como será demonstrado na pesquisa realizada no Governo do Estado do Espírito Santo.

\section{Estratégia Metodológica do Estudo Empírico}

Tomando-se como ponto de partida o conceito de dualidade da estrutura, serão 
agora discutidos os resultados de um estudo empírico que procurou mostrar, por intermédio da identificação de um conjunto de práticas sociais compartilhadas por determinados atores organizacionais, como a ação desses mesmos atores estava ancorada em propriedades estruturais da sociedade brasileira.

A orientação metodológica contemplou a indissociabilidade da conduta humana da estrutura social. Conforme sugere Giddens (1979, 1984), a utilização da Teoria da Estruturação como pano de fundo deste estudo, permite o enquadramento metodológico da pesquisa em dois níveis: a análise institucional e a análise da conduta estratégica. Tradicionalmente excludentes, o primeiro nível trata as propriedades estruturais como características dos sistemas sociais que são reproduzidas de forma crônica: o foco é centrado nas estruturas. O segundo tem que ver com o modo pelo qual os atores sociais monitoram reflexivamente seus atos, apoiando-se em propriedades estruturais na constituição de relações sociais: o foco aqui é centrado na agência humana, assumindo-se, em nível epistemológico, as propriedades estruturais como supostamente dadas. No caso deste artigo, analisar a conduta estratégica dos gerentes públicos é explicar como eles, agentes cognoscitivos, utilizam propriedades estruturais da sociedade brasileira para a construção de relações sociais nos cotidianos organizacionais. Assim, a pesquisa empírica, ainda que enfatizando o nível de análise da conduta estratégica dos gerentes públicos, leva em consideração o seu vínculo com elementos da estrutura.

A pesquisa, em forma de Estudo de Caso (Yin, 1994), foi feita nas Secretarias de Estado do Governo do Espírito Santo, tendo em vista ser este um Estado que oferecia uma alternativa interessante ao problema eleito, já que no período de janeiro de 1995 a dezembro de 1998, vivenciou experiências em torno da implantação da chamada Administração Pública Gerencial, preconizada por Bresser Pereira (1996), tornando-se importante o conhecimento das práticas sociais compartilhadas pelos seus gerentes em face das possíveis pressões em seus comportamentos, provocadas por aquelas mesmas mudanças organizacionais.

As unidades de análise da pesquisa foram constituídas por gerentes públicos. Assim o universo da pesquisa empírica foi formado pelos ocupantes de cargos de chefia do Governo Estadual em Secretarias de Estado, considerando-se aqueles que já viessem exercendo função gerencial por tempo mínimo de dois anos, a partir de janeiro de 1995. Optou-se por estratificar os ocupantes de função gerencial em três níveis distintos: Alta Gerência (AG) - Chefes de Gabinete e Subsecretários; Gerência Intermediária (GI) - Superintendentes, Coordenadores e Subcoordenadores; Gerência de Linha (GL) - Chefias de Grupos Setoriais e de Departamento. Do total de cento e setenta três cargos gerenciais somente setenta e sete de seus ocupantes $(44,5 \%)$ atendiam à exigência de, no mínimo, dois anos na função. A amostra definida então foi a do tipo não-probabilística, atingindo-se 
representantes de todas as Secretarias. A coleta dos dados deu-se por meio de entrevistas com roteiro semi-estruturado, alcançando-se a saturação e recorrência de informações na vigésima quinta entrevista. $\mathrm{O}$ tratamento dos dados levantados pelas entrevistas semi-estruturadas apoiou-se na concepção da análise de conteúdo. As entrevistas foram gravadas, transcritas integralmente e então codificadas e categorizadas (Bardin, 1996).

\section{Análise dos Dados à luz da Teoria da Estruturação}

\section{As Práticas Sociais Compartilhadas: Ação Gerencial e Raízes Brasileiras}

A partir da uma imersão nos universos teóricos de estudos sobre a sociedade brasileira, em que autores como Ramos (1983), Faoro (1987), Da Matta (1990, 1993), Freyre (1994), Holanda (1995) e Ribeiro (1996) apontam processos históricosociais que deram origem a traços marcantes da cultura nacional, foi identificado, com base em dados da pesquisa empírica, um conjunto de práticas sociais, compartilhadas pelos gestores públicos entrevistados, destacando-se:

- A boa vizinhança - universo pouco propício à cooperação e troca de informações técnicas entre unidades organizacionais, gerando a necessidade de os gerentes desenvolverem relações pessoais e amizades como propriedades indispensáveis à facilitação do convívio profissional.

O sincretismo casa/rua - a não distinção entre o espaço em que predominam valores ligados às relações familiares, à hierarquia patriarcal e à pessoalidade (a idéia da casa) e o mundo dominado pela impessoalidade, pelos decretos e regulamentos (a rua), caracterizando uma representação das organizações públicas para os gerentes como uma segunda casa ou uma grande família e, ao mesmo tempo, como local de conflitos e de definição de estratégias pelas quais lutam para a própria sobrevivência nos cargos.

. O controle cordial - o uso de relações afetuosas para o controle de subordinados, buscando-se evitar ao máximo as situações de conflito direto, tendo em vista a dificuldade para a aplicação de regras impessoais para a punição de insubordinados, atos esses que passam a ser tomados como de cunho pessoal, como atesta um depoimento marcante em que um gerente é visto como perseguidor, até por seus próprios pares, quando se viu obrigado a transferir de setor uma funcionária que não se adaptava aos padrões estabelecidos. 
- A contemporização - a transigência no dia-a-dia organizacional é comum, tornando-se habitual deixar as coisas como estão, originando-se daí atitudes próximas à acomodação, à condescendência, ao não enfrentamento de conflitos diretos, originando o jogo de cintura como um recurso fundamental nas situações embaraçosas.

- O plantador de coco - a dificuldade para conviver com o planejamento das atividades cotidianas, imperando as situações de emergência, o "apaga incêndio" e as prioridades que mudam ao gosto dos governantes, demonstradas muito bem pela metáfora utilizada por um dos entrevistados que comparou os gerentes e governantes públicos a plantadores de coco que, diferentes dos plantadores de carvalho, cuja madeira de lei leva tempo para chegar à maturidade, querem resultados sempre imediatos, como no cultivo do coco que não leva tantos anos para dar bons frutos.

. O faz-de-conta - prática que sinaliza para espaços organizacionais em que não são privilegiadas avaliações formais de desempenhos individuais ou coletivos, ou seja, dificilmente são medidos metas e alcance de resultados, valendo mesmo a informalidade, a conversa informal, como no caso de um entrevistado que declarou que o seu chefe imediato lhe outorgava notas de acordo com critérios que arbitrava cada dia.

. O manda-chuva - um conjunto de relações entre superiores e subordinados em que o "manda quem pode, obedece quem tem juízo" é o lema básico, caracterizando-se universos organizacionais marcados pelo autoritarismo e centralização do poder nos pontos mais altos da hierarquia.

. O dar a volta por cima - situação em que se torna comum o uso do jeitinho como recurso indispensável para a convivência com os excessos de normas e decretos formais, caracterizando situações nas quais as relações pessoais, as amizades facilitam o contorno de dificuldade para a obtenção de resultados pelos caminhos formais.

Esse conjunto de práticas permite caracterizar os cenários organizacionais do setor público pesquisado com tendências a alto grau de centralização de poder; pelo baixo nível de cooperação interna entre unidades administrativas; pela não primazia da definição de metas, controle e cobrança de resultados organizacionais eficazes, predominando o imediatismo; bem como pela miscigenação entre a pessoalidade e a impessoalidade no trato cotidiano. As práticas sociais daí decorrentes representam nada mais que o resultado de como os gerentes, a partir dos "estoques de conhecimentos" (Giddens, 1984) que dispõem desses mesmos cenários, referentes a traços típicos da sociedade e da gestão pública brasileiras, criam e recriam condutas que lhes permitem prosseguir como gerentes. 


\section{Ação Gerencial e o Modelo da Dualidade da Estrutura em Interação}

As práticas sociais descritas e que orientam a ação dos gerentes pesquisados evidenciam a dualidade da estrutura em interação (Giddens, 1979, 1984), ou seja, o vínculo entre a ação gerencial e as propriedades estruturais da sociedade brasileira - suas raízes histórico-sociais. Dito de outra maneira, a conduta dos gerentes não é determinada por aquelas mesmas raízes, mas condicionada por elas, à medida que habilitam e restringem a ação de atores organizacionais cognoscitivos, ou seja, que sabem como prosseguir, tendo em vista o conhecimento que delas possuem. Esse processo será apresentada pelo modelo da Dualidade da Estrutura em Interação (Giddens, 1984), a partir de dados coletados empiricamente e a seguir representados graficamente nos Quadros 1, 2 e 3, permitindo a visualização das condutas gerenciais e os domínios da estrutura e da interação, mediados, ainda que só metodologicamente, pelas modalidades responsáveis pela ligação entre aqueles dois domínios.

\section{Quadro 1: Condutas Gerenciais - o Vínculo Estrutura e Ação}

\begin{tabular}{|c|c|c|c|c|c|}
\hline $\begin{array}{l}\text { Condutas } \\
\text { gerenciais }\end{array}$ & Estrutura & & Modalidades & & Interação \\
\hline \multirow{8}{*}{$\begin{array}{l}\text { "Boa } \\
\text { vizinhança" } \\
\text { O "manda- } \\
\text { chuva" }\end{array}$} & Significação & \multirow[t]{2}{*}{$\stackrel{\leftarrow}{\rightarrow}$} & $\begin{array}{l}\text { Esquemas de } \\
\text { interpretação }\end{array}$ & \multirow[t]{2}{*}{$\begin{array}{l}\leftarrow \\
\rightarrow\end{array}$} & $\begin{array}{l}\text { Comunicação de } \\
\text { significados }\end{array}$ \\
\hline & $\begin{array}{c}\text { Universo organizacional: } \\
\text { fragmentado/ pouco } \\
\text { cooperativo }\end{array}$ & & $\begin{array}{l}\text { Dificuldades para } \\
\text { acesso a dados } \\
\text { Falta de visão do } \\
\text { todo }\end{array}$ & & $\begin{array}{l}\text { Intransigência } \\
\text { Desinformação }\end{array}$ \\
\hline & $\downarrow \uparrow$ & & $\downarrow \uparrow$ & & $\downarrow \uparrow$ \\
\hline & Dominação & \multirow[t]{2}{*}{$\stackrel{\leftarrow}{\rightarrow}$} & $\begin{array}{l}\text { Facilidades } \\
\text { (Recursos) }\end{array}$ & \multirow[t]{2}{*}{$\begin{array}{l}\leftarrow \\
\rightarrow\end{array}$} & Poder \\
\hline & $\begin{array}{c}\text { A capacidade para filtrar } \\
\text { interesses }\end{array}$ & & $\begin{array}{c}\text { Amizade / } \\
\text { pessoalidade } \\
\text { Status } \text { hierárquico }\end{array}$ & & $\begin{array}{l}\text { Autoridade para } \\
\text { controle de pessoas e } \\
\text { informações } \\
\text { ("manda quem } \\
\text { pode...") }\end{array}$ \\
\hline & $\downarrow \uparrow$ & \multirow{3}{*}{$\begin{array}{l}\leftarrow \\
\rightarrow\end{array}$} & $\downarrow \uparrow$ & \multirow{3}{*}{$\begin{array}{l}\leftarrow \\
\rightarrow\end{array}$} & $\downarrow \uparrow$ \\
\hline & Legitimação & & Regras (normas) & & Sanção \\
\hline & $\begin{array}{c}\text { Centralização/ } \\
\text { "departamentalização” }\end{array}$ & & $\begin{array}{l}\text { Isolamento entre } \\
\text { unidades } \\
\text { organizacionais } \\
\text { Autoritarismo }\end{array}$ & & $\begin{array}{l}\text { Baixo nível de } \\
\text { integração } \\
\text { organizacional }\end{array}$ \\
\hline
\end{tabular}


O Quadro 1 apresenta as condutas gerenciais inerentes à boa vizinhança e ao manda-chuva, podendo-se nele verificar no domínio da estrutura a significação de um universo organizacional fragmentado, avesso à visão sistêmica de integração que, por sua vez, é interpretado pelos gerentes como espaço de difícil acesso a dados, bem como de reduzida capacidade de cada um para uma visão ampla do todo. Daí que nas interações cotidianas se comunicam esses significados por meio da intransigência - pouca troca de informações, resistência à cooperação entre pares - e desinformação do que acontece no plano das políticas estratégicas de governo para cada unidade organizacional. No campo da dominação predomina forte capacidade do gerente para filtrar interesses, utilizando como recursos a pessoalidade, o status hierárquico, permitindo-lhe o exercício do poder, controlando informações privilegiadas pouco socializadas e exercendo autoridade sobre subordinados pelo cultivo de relações amigáveis e pelo uso do status do cargo. É legitimada assim a centralização do poder, bem como a departamentalização excessiva - a idéia de "cada um por si", definindo-se como regra o isolamento entre as unidades organizacionais, sancionando-se no plano da interação um baixo nível de integração organizacional, ou seja, unidades e seus atores com reduzidas articulações para temas do trabalho diário.

\section{Quadro 2: Condutas Gerenciais - o Vínculo Estrutura e Ação}

\begin{tabular}{|c|c|c|c|c|c|}
\hline $\begin{array}{l}\text { Condutas } \\
\text { gerenciais }\end{array}$ & Estrutura & & Modalidades & & Interação \\
\hline \multirow{8}{*}{$\begin{array}{l}\text { Sincretismo } \\
\text { "casa/rua" }\end{array}$} & Significação & \multirow[t]{2}{*}{$\stackrel{\leftarrow}{\rightarrow}$} & $\begin{array}{l}\text { Esquemas de } \\
\text { interpretação }\end{array}$ & \multirow[t]{2}{*}{$\stackrel{\leftarrow}{\rightarrow}$} & $\begin{array}{l}\text { Comunicação de } \\
\text { significados }\end{array}$ \\
\hline & $\begin{array}{l}\text { Organização: extensão } \\
\text { do mundo familiar }\end{array}$ & & $\begin{array}{l}\text { "Segunda casa" } \\
\text { Grande família } \\
\text { Luta pela } \\
\text { sobrevivência }\end{array}$ & & $\begin{array}{l}\text { Fusão: espaços } \\
\text { "públicos"e } \\
\text { "privado" }\end{array}$ \\
\hline & $\downarrow \uparrow$ & \multirow[b]{2}{*}{$\stackrel{\leftarrow}{\rightarrow}$} & $\downarrow \uparrow$ & \multirow{3}{*}{$\begin{array}{l}\leftarrow \\
\rightarrow\end{array}$} & $\downarrow \uparrow$ \\
\hline & Dominação & & $\begin{array}{l}\text { Facilidades } \\
\text { (Recursos) }\end{array}$ & & Poder \\
\hline & O "homem cordial" & & $\begin{array}{c}\text { Proximidade e } \\
\text { intimidade pessoal } \\
\text { Conversas informais }\end{array}$ & & $\begin{array}{c}\text { Alta } \\
\text { discricionariedade }\end{array}$ \\
\hline & $\downarrow \uparrow$ & \multirow{3}{*}{$\begin{array}{l}\leftarrow \\
\rightarrow\end{array}$} & $\downarrow \uparrow$ & \multirow{3}{*}{$\stackrel{\leftarrow}{\rightarrow}$} & $\downarrow \uparrow$ \\
\hline & Legitimação & & Regras (normas) & & Sanção \\
\hline & $\begin{array}{l}\text { "Patriarcalismo" } \\
\text { Pessoa e indivíduo }\end{array}$ & & $\begin{array}{l}\text { Pessoalidade } \\
\text { Afetividade: } \\
\text { cordialidade }\end{array}$ & & Afeto e violência \\
\hline
\end{tabular}




\section{Quadro 3: Condutas Gerenciais - o Vínculo Estrutura e Ação}

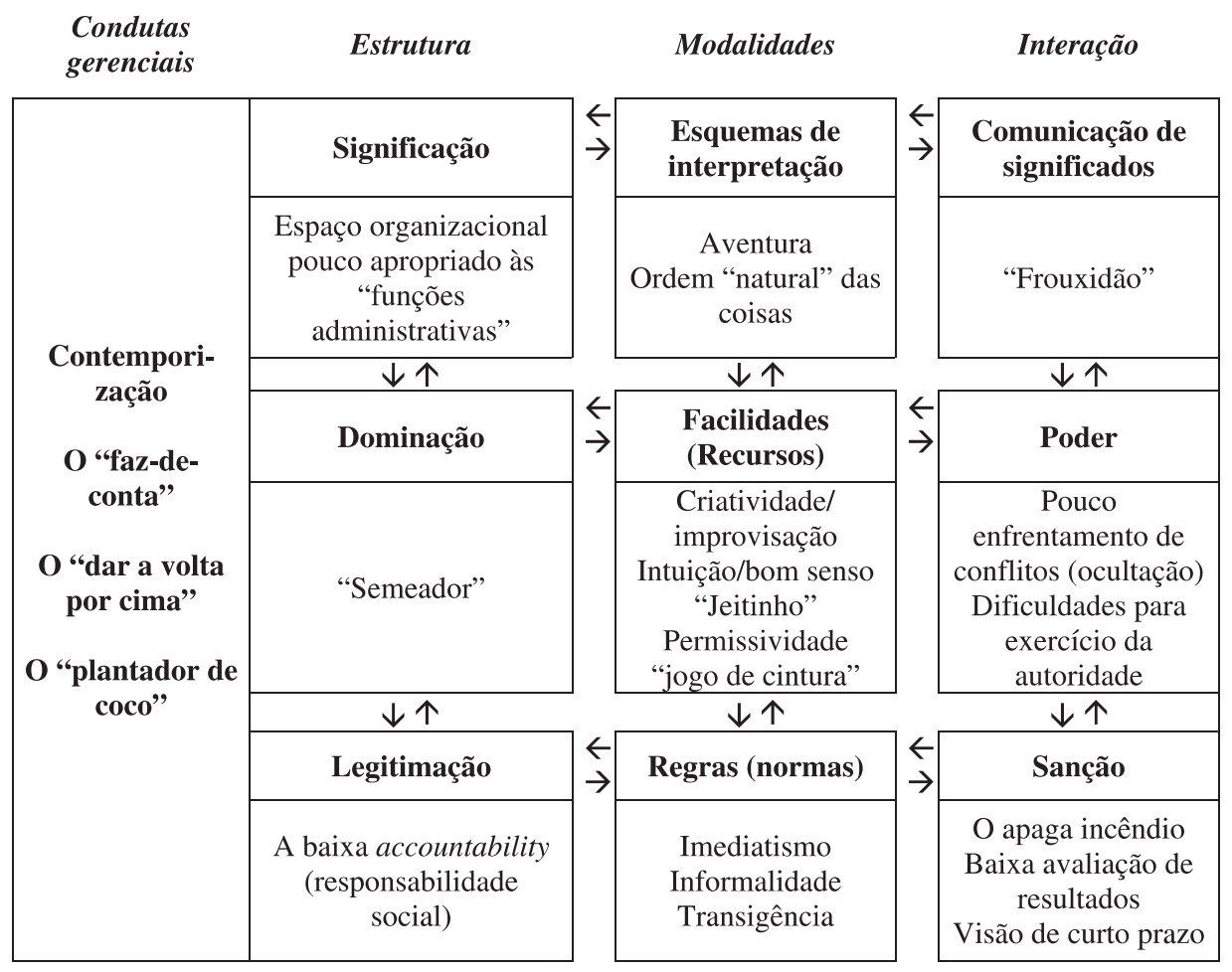

No Quadro 2 as condutas relativas ao sincretismo casa/rua e controle cordial resultam de uma significação do universo organizacional como extensão do mundo familiar, em que os atores o interpretam como segunda casa ou grande família, ao mesmo tempo que o local de luta pela sobrevivência - o mundo do trabalho, impessoal (Da Matta, 1990, 1993). A comunicação desses significados é marcada por hibridismo entre os espaços público - impessoal e privado - pessoal. No plano da dominação predomina a cordialidade (Holanda, 1995), isto é, por meio de recursos como a proximidade, intimidade pessoal e conversas informais, os gerentes conseguem mais facilmente o cumprimento de obrigações por parte de seus subordinados, construindo ambientes em que são contornados e evitados conflitos diretos, exercendo um tipo de poder com alto teor de discricionariedade, isto é, muito influenciado por discriminações, pelas quais os mais chegados recebem um tipo de tratamento diferenciado daqueles mais distantes. Legitimamse assim, nos espaços organizacionais, traços de uma herança patriarcal, do predomínio da pessoa sobre o indivíduo (Da Matta, 1990, 1993), em que as normas que guiam a ação humana passam a ser a pessoalidade, destacando-se a afetividade como traço característico da cordialidade (Holanda, 1995). Sancionam-se, como características da interação, o afeto e a violência, ou seja, o 
gerente, ao mesmo tempo que é afetivo e discricionário, pode usar de sua autoridade impessoal de modo mais vigoroso, para fazer cumprir o que deseja, tendo em vista que sua discricionariedade permite navegar socialmente de um pólo a outro.

No Quadro 3 destacam-se as condutas relativas à contemporização, ao fazde-conta, ao "dar a volta por cima" e ao plantador de coco. Elas se destacam pela significação de espaços organizacionais pouco apropriados às ditas "funções administrativas" (Fayol, 1970) nos quais são possíveis a definição de esquemas interpretativos vinculados à uma certa "ordem natural das coisas", isto é, uma dose de savoir faire dos atores organizacionais que lhes permite agir em função de manter o status quo das rotinas administrativas e relações sociais sem muito questionamento, provocando interações marcadas por certa frouxidão, ou seja, por uma dificuldade para enfrentamento de mudanças e conflitos com vistas a novos empreendimentos. Assim predomina a ocorrência de pouca definição de metas e objetivos a alcançar, bem como do conseqüente controle e avaliação formal de resultados alcançados e por alcançar.

No plano da dominação o Quadro 3 permite destacar a aproximação ao tipo ideal do semeador (Holanda, 1995), caracterizado por ação gerencial impregnada pelo gosto da aventura, já que pouco provida da idéia de longo prazo e visão de futuro, sendo comum o "cada um por si", o "correr atrás" do cumprimento de tarefas e alcance de resultados descolados de uma política organizacional estratégica e integrada. Os recursos disponíveis apontam para o uso da criatividade, improvisação, bom senso, jeitinho, permissividade e jogo de cintura, destacandose no plano da interação o pouco enfrentamento de conflitos ou até mesmo a sua ocultação, definindo certas dificuldades para o exercício da autoridade gerencial. Legitima-se, assim, a tendência a uma baixa responsabilidade social no sentido do alcance de resultados organizacionais, em que regras como o imediatismo, a informalidade e a transigência ou o conformismo sancionam universos de trabalho em que sobressaem o "apaga incêndio" e a visão de curto prazo.

Assim as representações gráficas mostraram como se dá o processo de estruturação do fenômeno inerente ao exercício da prática gerencial nas organizações estudadas, ou seja, a compreensão de como a ação humana não é determinada pela estrutura social, mas por ela condicionada. Os gerentes não agem como que descolados de contextos histórico-sociais, mas, por meio de sua cognoscitividade, ancoram-se em propriedades estruturais da sociedade brasileira, sabendo muito bem como utilizá-las para prosseguir na vida social. Dito de outro modo, raízes do processo histórico-social brasileiro, trespassando o plano organizacional, fornecem guias para que determinados processos de significação, dominação e legitimação propiciem a construção da ação gerencial cotidiana. 
Os gerentes, por meio da utilização das modalidades identificadas nos três Quadros 1,2 e 3, constroem o seu modo de agir, ora limitados e ora habilitados pelas mesmas propriedades estruturais. O semeador, por exemplo, limitado por um espaço organizacional pouco propício ao planejamento, é o mesmo que desafia aquela função administrativa, utilizando-se de sua capacidade criativa e intuitiva para o alcance de resultados. Logo a limitação que dificulta o uso de ferramenta racional, habilita o desenvolvimento da intuição para a construção da ação e assim por diante, no que tange às condutas identificadas naqueles mesmos quadros.

\section{Conclusóes}

As condutas gerenciais levantadas nas organizações estatais pesquisadas comprovaram a hipótese de que a ação cotidiana dos gerentes é condicionada por propriedades estruturais da sociedade brasileira, deixando claro, como ensina a Teoria da Estruturação, como aquela mesma ação não se dá ao acaso, mas reflete características de um determinado contexto histórico-social. Por meio dessa constatação, agrega-se uma contribuição para a pesquisa em Administração, em particular no tocante à temática da mudança organizacional, mostrando que dificilmente ela pode realmente efetivar-se, desconhecido aquele mesmo contexto.

As práticas sociais identificadas na pesquisa permitem ainda a constatação de que os ambientes organizacionais em que os gerentes atuam no setor público, são marcados pelo autoritarismo, pelo baixo nível de cooperação interna entre unidades administrativas, pela não primazia da definição de metas, bem como de controles e cobranças de resultados organizacionais eficazes. Os gerentes, a partir dos estoques de conhecimentos que dispõem daqueles mesmos ambientes organizacionais, ou seja, da sua cognoscitividade (Giddens, 1989), criam e recriam condutas que lhes permitem prosseguir como gerentes, ou seja, que garantem a sua sobrevivência nos cargos, não cabendo julgamento valorativo no sentido de que eles sejam profissionais mal intencionados ou incapazes. Mais do que certas ou erradas, eficazes ou ineficazes, as práticas sociais demonstram como os gerentes se utilizam de seus saberes sociais comuns, construídos e legitimados socialmente, tornando possível a continuidade da rotina da gestão organizacional cotidiana.

Por outro lado, dado o conceito da dualidade da estrutura, fica claro que as propriedades estruturais tanto facilitam como restringem a ação humana. Dessa forma, a cordialidade, a criatividade, a afetividade, a pessoalidade, a transigência, 
que tornam possível a ação dos gerentes, são as mesmas propriedades facilitadoras à construção de organizações públicas mais sintonizadas com os cidadãoscontribuintes, à medida que processos de mudança sejam capazes de tomá-las como propriedades que podem criar condições para o desenvolvimento de novas condutas gerenciais.

Os Quadros 1, 2, e 3 permitem ainda, sem a intenção de criar estereótipos, a aproximação a um perfil gerencial, nas organizações estudadas, englobando as seguintes características: autodidata na formação gerencial; cordial - usa o coração e a razão; contemporizador - procura evitar conflitos diretos; acostumado ao imediatismo - semeador, nos moldes de Holanda (1995); criativo e sensível às suas intuições; habituado ao sincretismo casa e rua - ao pessoal e impessoal (Da Matta, 1990, 1993) e versátil para contornar regulamentos formais sem fugir à legalidade. Pode-se, a partir daí, sugerir novas pesquisas que tratem especificamente da recorrência de traços inerentes ao perfil aqui sugerido em outras organizações públicas ou privadas, buscando-se, por exemplo, como eles se aproximam ou se distanciam desse mesmo perfil, tendo em vista o contexto histórico-social brasileiro e, por outro lado, as especificidades de cada organização estudada.

Utilizando-se ainda a Teoria da Estruturação e por meio de uma coleta de dados que agregue a técnica da observação, pode ser possível enriquecer ainda mais os resultados aqui apresentados, no sentido de identificação de processos pelos quais, por meio da dualidade da estrutura, os atores organizacionais não só contribuem para a reprodução de propriedades estruturais, mas também como, a partir delas próprias, podem ser capazes de produzir novas práticas e condutas gerenciais; por exemplo, quando submetidos a algum tipo de pressão por mudanças organizacionais. A limitação deste estudo ao uso de entrevistas não permite ir tão longe, mas indica algumas pistas que podem enriquecer futuros estudos.

Considerando-se que, no complexo mundo das organizações públicas e privadas contemporâneas, se faz mister a definição de alternativas que possibilitem ações estratégicas mais voltadas para realidades locais, que possam articular modelos de gestão, portadores de ferramentas referenciais universais, com o dia-a-dia das organizações, embebidas estas últimas pelos traços típicos das sociedades em que se inserem, o uso da Teoria da Estruturação como instrumento teóricometodológico de análise, pode ser um bom caminho. 


\section{ReferênCias Bibliográficas}

ALVESSON, M.;

WILLMOTT, H.

Making sense of management: a critical introduction. London: Sage Publications, 1996.

BARDIN, L.

L'analyse de contenu. 8.ed. Paris: Puf, 1996.

BRESSER PEREIRA, L. C.

$\mathrm{Da}$ administração pública burocrática à gerencial. Revista do Serviço Público, v. 47, n.1, p. 7-29, 1996.

DA MATTA, R.

Carnavais, malandros e heróis: para uma sociologia do dilema brasileiro. 5.ed. Rio de Janeiro: Guanabara, 1990.

O que faz o Brasil, Brasil? 5.ed. Rio de Janeiro: Rocco, 1993.

FAORO, R.

Os donos do poder. 7.ed. Porto Alegre: Globo, 1987.

FAYOL, H.

Administração industrial e geral. 8.ed. São Paulo: Atlas, 1970.

FREYRE, G.

Casa grande e senzala. 29.ed. Rio de Janeiro: Record, 1994.
GIDDENS, A.

Central problems in social theory. Berkeley: University of California Press, 1979.

The constitution of society. Berkeley: University of California Press, 1984.

The nation-state and violence. Berkeley: University of California Press, 1987.

A constituição da sociedade. São Paulo: Martins Fontes, 1989.

Novas regras do método sociológico. 2.ed. Lisboa: Gradiva, 1996.

GOFFMAN, E.

The interaction order. American Sociological Review, v. 48, n. 1, p. 1-17, 1983.

HOLANDA, S.

Raízes do Brasil. São Paulo:

Companhia das Letras, 1995.

ORLIKOWSKY, W. J.

The duality of technology: rethinking the concept of technology in organizations. Organization Science, v. 3, n. 3, p. 398-427, Aug. 1992. 
ORLIKOWSKY, W.; ROBEY, D.

Information technology and the structuring of organizations.

Information

Systems

Research, v. 2, n. 2, p. 143-169, 1991.

RAMOS, G.

Administração e contexto brasileiro: esboço de uma teoria geral da administração. 2.ed. Rio de Janeiro: Fundação Getulio Vargas, 1983.

REED, M.

The sociology of management. London: Harvester Wheatsheaf, 1989.

RIBEIRO, D.

O povo brasileiro: a formação e o sentido do Brasil. 2.ed. São Paulo: Companhia das Letras, 1996.

ROULEAU, L.

La structuration sociale de l'activité stratégique: le cas Irving Samuel/ Jean-Claude Poitras. Montreal, 1995. Tese (Doutorado em Administração) École des Hautes Études Commerciales.

ROULEAU, L.;

JUNQUILHO, G. S.

Annalyse organisationnelle et théorie de la structuration: le renouvellement $\mathrm{du}$ projet moderniste. In : ENCONTRO
ANUAL DA ANPAD, 22., 1998, Foz do Iguaçu. Anais... Foz do Iguaçu: ANPAD, 1998. 1 CDROM.

SAHAY, S.;

WALSHAM, G.

Social structure and managerial agency. Organization Studies, v. 18, n. 3, p. 415-444, 1997.

SARASON, Y.

A model of organizational transformation: the incorporation of organizational identity into a structuration theory framework. Academy of Management Journal, p. 47-51, 1995.

SIMARD, P.

Esquisse d'une théorie structurationniste des organisations. Montreal, 1992. Dissertação (Mestrado em Administração) - École des Hautes Études Commerciales.

STEWART, R.

Studies of managerial jobs and behavior. Journal of Management Studies, v. 26, n. 1, p. 1-10, 1989.

WATSON, T.

In search of management: culture, chaos and control in managerial work. London: Routledge, 1994. 
WHITLEY, R.

On the nature of managerial tasks and skills: their distinguishing characteristics and organization. Journal of Management Studies, v. 26, n. 3, p. 209-224, 1989.

\section{WHITTINGTON, R.}

Putting Giddens into action: social systems and managerial agency. Journal of Management Studies, v. 29, n. 6, p. 693-712, 1992.
WILLMOTT, H. C.

The structuring of organizational structure: a note. Administrative Science Quarterly, v. 26, p. 470474, 1981.

Studying managerial work: a critique and a proposal. Journal of Management Studies, v. 24, n. 3, p. 249-269, 1987.

YIN, R. K.

Case study research: design and methods. 2.ed. London: Sage Publications, 1994. 